Ann. Geophysicae 16, 828-837 (1998) @ EGS - Springer-Verlag 1998

\title{
The summertime 12-h wind oscillation with zonal wavenumber $s=1$ in the lower thermosphere over the South Pole
}

\author{
Y. I. Portnyagin ${ }^{1}$, J. M. Forbes ${ }^{2}$, N. A. Makarov ${ }^{1}$ E. G. Merzlyakov ${ }^{1}$, S. Palo ${ }^{2}$ \\ ${ }^{1}$ Institute for Experimental Meteorology, Obninsk, Russia \\ ${ }^{2}$ Department of Aerospace Engineering Sciences, Campus Box 429, University of Colorado, Boulder, CO 80303-0429 USA
}

Received: 26 September 1997 / Revised: 23 January 1998 / Accepted: 2 February 1998

\begin{abstract}
Meteor radar measurements of winds near $95 \mathrm{~km}$ in four azimuth directions from the geographic South Pole are analyzed to reveal characteristics of the 12-h oscillation with zonal wavenumber one $(s=1)$. The wind measurements are confined to the periods from 19 January 1995 through 26 January 1996 and from 21 November 1996 through 27 January 1997. The 12-h $s=1$ oscillation is found to be a predominantly summertime phenomenon, and is replaced in winter by a spectrum of oscillations with periods between 6 and $11.5 \mathrm{~h}$. Both summers are characterized by minimum amplitudes $\left(5-10 \mathrm{~ms}^{-1}\right)$ during early January and maxima $\left(15-20 \mathrm{~ms}^{-1}\right)$ in November and late January. For 10-day means of the 12-h oscillation, smooth evolutions of phase of order 4-6 h occur during the course of the summer. In addition, there is considerable day-to-day variability $\left( \pm 5-10 \mathrm{~ms}^{-1}\right.$ in amplitude) with distinct periods (i.e., $\sim 5$ days and $\sim 8$ days) which suggests modulation by planetary-scale disturbances. A comparison of climatological data from Scott Base, Molodezhnaya, and Mawson stations suggests that the 12-h oscillation near $78^{\circ} \mathrm{S}$ is $s=1$, but that at $68^{\circ} \mathrm{S}$ there is probably a mixture between $s=1$ and other zonal wavenumber oscillations (most probably $s=2$ ). The mechanism responsible for the existence of the 12-h $s=1$ oscillation has not yet been identified. Possible origins discussed herein include in situ excitation, nonlinear interaction between the migrating semidiurnal tide and a stationary $s=1$ feature, and thermal excitation in the troposphere.
\end{abstract}

Key words. Meteorology and atmospheric dynamics . Middle atmosphere dynamics - Thermospheric dynamics $\cdot$ Waves and tides

Correspondence to: J. M. Forbes

\section{Introduction}

There exist only a few works which address the dynamics of the neutral upper mesosphere/lower thermosphere (MLT) over the South Pole. Among these are the pioneering works of Hernandez et al. (1992a,b, 1993, 1995) and Fraser et al. (1993) which are based upon optical observations of the winds and $\mathrm{OH}$-emission rates near the mesopause (ca. 85-100 km). Some understanding of basic atmospheric motions in the MLT region close to the rotational poles has emerged from these studies. For example, these works demonstrate that the flow field in the vicinity of the geographical poles possesses a zonal wavenumber - one structure, while the structure of scalar variables (such as temperature and $\mathrm{OH}$-emission rates) are of zonal wavenumber - zero character. The measurements have also noted the wintertime presence of westward-propagating oscillations with periods near 10 and $12 \mathrm{~h}$, and also 2-4-day eastward propagating oscillations. However, the aforementioned optical techniques are limited in their ability to carry out long-term continuous measurements (clear sky conditions in absence of significant sun and moon illumination of the sampling volumes). As a result, no wind measurements have been made in the MLT region over the South Pole during the austral summer months prior to the present series of observations.

In January 1995, through collaborative efforts between the University of Colorado (Boulder, USA) and the Institute for Experimental Meteorology (Obninsk, Russia), a meteor radar capable of continuously measuring winds near $95 \mathrm{~km}$ in four azimuth directions (longitudinal meridians $0^{\circ}, 90^{\circ} \mathrm{E}, 180^{\circ}$, and $90^{\circ} \mathrm{W}$ ) was installed at Amundsen-Scott Station at the South Pole. The radar operated continuously until 26 January 1996, thus providing horizontal wind measurements covering all seasons of the year. Preliminary findings from these observations have been documented by Forbes et al. (1995), Portnyagin et al. (1996, 1997), and Hernandez 
et al. (1996). Due to the importance of this data set, especially in light of the summer observations, operation of the radar was resumed for the next summer season (November 1996-January 1997) to confirm our initial findings.

The focus of this paper is on the seasonal and intraseasonal behavior of the semidiurnal wind oscillation with wavenumber $s=1$ which dominates the meridional wind field during the austral summer. A preliminary description of this oscillation is provided by Forbes et al. (1995) and Portnyagin et al. (1996). In Sect. 2 we describe the meteor radar system and its operational capabilities. The measurement results are discussed in Sect. 3 and interpretation of these results are provided in Sect. 4. Conclusions are made in the final part of the paper.

\section{The radar system}

An error analysis of the South Pole meteor wind observations is provided in Portnyagin et al. (1997). A brief description of the meteor radar system, its operation, and errors in the wind measurements are provided in the following. Additional details may be found in Portnyagin et al. (1997).

The meteor radar was developed at the Institute for Experimental Meteorology (Obninsk, Russia). As for all types of meteor radars, the line-of-sight wind velocities are obtained by measuring the Doppler shift of coherent radio reflections from the ionized meteor trails produced by meteoroid ablation in the upper atmosphere. The meteor trails are several $\mathrm{km}$ in length, with an initial radius of about $1 \mathrm{~m}$. The hourly mean winds, which are assumed to be horizontal, represent Gaussian-weighted averages centered near $95 \mathrm{~km}$ above sea level with halfwidth of about $10 \mathrm{~km}$. Therefore, no information is provided concerning the vertical structure of the wind field. The radar operated at $33.6 \mathrm{MHz}$ with a pulse power of about $8 \mathrm{~kW}$ and an average power of $300 \mathrm{~W}$; the pulse duration is $120 \mathrm{~ms}$ and the pulse repetition frequencies (PRF) are 100 and $300 \mathrm{~Hz}$. The antenna system consists of four five-element transmitting/receiving Yagii antennae whose beams are directed along the four aforementioned geographic longitude meridians. In the search mode, the atmosphere is "interrogated" at a PRF of $100 \mathrm{~Hz}$ for the appearance of meteor trails. When a meteor echo is detected in any direction, the search mode is stopped and pulses with a PRF of $300 \mathrm{~Hz}$ are radiated. The wind measurement is made from the trail, which takes about $0.1 \mathrm{~s}$. The system then returns to search mode. Meteor rates over the South Pole are comparable with those observed at other latitudes and are changing between about ten in evening hours to several hundreds in the morning hours. The probability of appearance of meteor reflections in two directions simultaneously is very low. As a result, along with the obvious advantage of making measurements in different directions independently, we do not lose any meteor rate statistics in any measurement direction as a result of our search/interrogate mode of operation.
The radar system contains a number of measures to ensure that "good" echoes, i.e., those that lead to reliable Doppler shifts (wind measurements), are selected while others are rejected. In particular, the interrogation/acquisition sequence automatically eliminates a number of spurious and unreliable echoes from the analysis. Auroral echoes have a number of characteristic features which allow them to be identified and then rejected. Antenna sidelobes are down about $10 \mathrm{~dB}$ : we estimate that less than 1 in 1000 echoes which are "accepted" originate from sidelobe contamination, and thus do not affect our analysis.

We have performed two experiments at the South Pole to verify proper operation of the meteor radar system, and its ability to infer neutral winds. First, the accuracy of the radar measurements was tested by determining the velocity of a specially deployed aircraft into the field of view of the radar antenna beam; for three different passages of the aircraft, the velocity determinations were accurate to $2 \%$ at the $99.9 \%$ significance level. Secondly, wind measurements using a co-located high-resolution infrared spectrometer during 19-30 June 1995 were perfomed and compared with the meteor radar wind measurements (Hernandez et al., 1996). (This spectrometer measures Doppler shifts in the night-sky emission of the $\mathrm{OH}$ (6-2) P1(2) line near $840 \mathrm{~nm}$, whose peak height of emission is near $88 \mathrm{~km}$ and has an emission layer width of about $10 \mathrm{~km}$.) During this period, daily mean winds showed agreement within the accuracies of the systems, and the correlation between individual measurements over this period was 0.79 at the significance level of $99.9 \%$ despite the different measurement heights.

With the radar located at the South Pole, the only wind component measurable is the meridional wind (northward positive). On average, 20 to 80 individual wind measurements are used to compute an hourly mean meridional wind estimate. On occasion the number of meteor returns can exceed 100 or be less than 10 , in any given direction. The mean square deviation of the hourly mean values is typically between 20 and $40 \mathrm{~ms}^{-1}$. As a result, errors in hourly wind determinations usually range between plus/minus 3 to $10 \mathrm{~ms}^{-1}$, depending on the hourly meteor rate.

\section{Measurement results}

During the period of operation there were only a few gaps in the measurements, which were made daily and independently of the weather conditions. As a result, the total duration of the gaps in the data did not exceed about $7 \%$. The high quality of the data permits us to use multiple techniques in the analysis of these data such as the periodogram and a least-squares harmonic analysis.

When analyzing these hourly data on a daily basis a harmonic least-squares fit is used. The periods used in the harmonic fit are determined from periodogram analyses. Typical errors at the 0.7 significance level for the amplitudes and phases of the significant intradiurnal oscillations are estimated at $3 \mathrm{~ms}^{-1}$ and $0.2 \mathrm{~h}$, respectively. 
Figure 1 illustrates the frequency content of the meridional wind field from the South Pole, as a function of time from January 1995 to January 1996. This figure was generated using a sliding periodogram, also referred to as a spectrogram. The spectrogram was formed by computing periodograms using 10-day segments of data where consecutive segments overlapped by 7 days. This creates a significant correlation between consecutive periodograms. The spectrograms for each of the four azimuth directions were averaged to yield the spectrogram in Fig. 1. The periodograms were computed using a 1024-point fast Fourier transform (FFT) where the 240 hourly points for every 10-day segment were zeropadded with 784 zeros added to the end of the data segment being analyzed. This oversampling in frequency provides a smoother, more continuous spectrum without affecting frequency content. No window function was applied, thereby minimizing smearing in the frequency domain, since no significant spectral signals were present near the 12-h period where sidelobe contamination would be expected. Note that the depiction in Fig. 1 provides no information on coherence between measurement directions or direction of zonal propagation.

The highlights of Fig. 1 are:

1. Obvious during all seasons, but with significantly weaker amplitudes during winter, is an oscillation with a period close to $24 \mathrm{~h}$, probably connected with the evanescent diurnal tide with $s=1$ typical of polar latitudes.

2. A strong summer time oscillation with 12-h period.

3. A spectrum of oscillations with periods less than $12 \mathrm{~h}$ lasting from April to October with a tendency for this part of the spectrum to broaden during winter.

4. A spectrum of oscillations with periods between 2 and 10 days from April to October with a tendency for this part of the spectrum to broaden during winter.

5. The absence of any significant oscillations with periods between 24 and $12 \mathrm{~h}$.

6. Two broadband events, one in April and one in November, which coincide with net wind divergences from the pole. The larger April event is discussed by Portnyagin et al. (1997).

(A more rigorous examination of these features in all four directions indicates oscillations in categories 1-3 are westward-propagating and those in category 4 are eastward propagating. Oscillations in categories 1, 3, and 4 are planned to be the subjects of future reports by the authors.)

It is clear from Fig. 1 that the 12-h oscillation observed at the South Pole obtains its largest amplitudes in the summer months (October through February). The 10-day averages of the semidiurnal amplitudes and phases, resulting from a harmonic analysis of the data for the periods 1 October 1995 to 26 January 1996 and 19 January 1995 to 18 February 1995, are shown for all directions in Fig. 2. The phases for each azimuth direction were reduced to one direction in this figure. This was accomplished by subtracting 3, 6 and $9 \mathrm{~h}$ from the phase values for the three subsequent observing directions, in the order consistent with a westwardpropagating zonal wavenumber-one disturbance. It can be seen from this figure that the seasonal behavior of the amplitudes for different measurement directions are very similar with two maxima and one minimum. An intraseasonal behavior of the phases is also observed, with a very strong course from October to February. The average phase shift between the phases for consequent directions throughout the whole observational period is practically constant and equal to about $3 \mathrm{~h}$. As

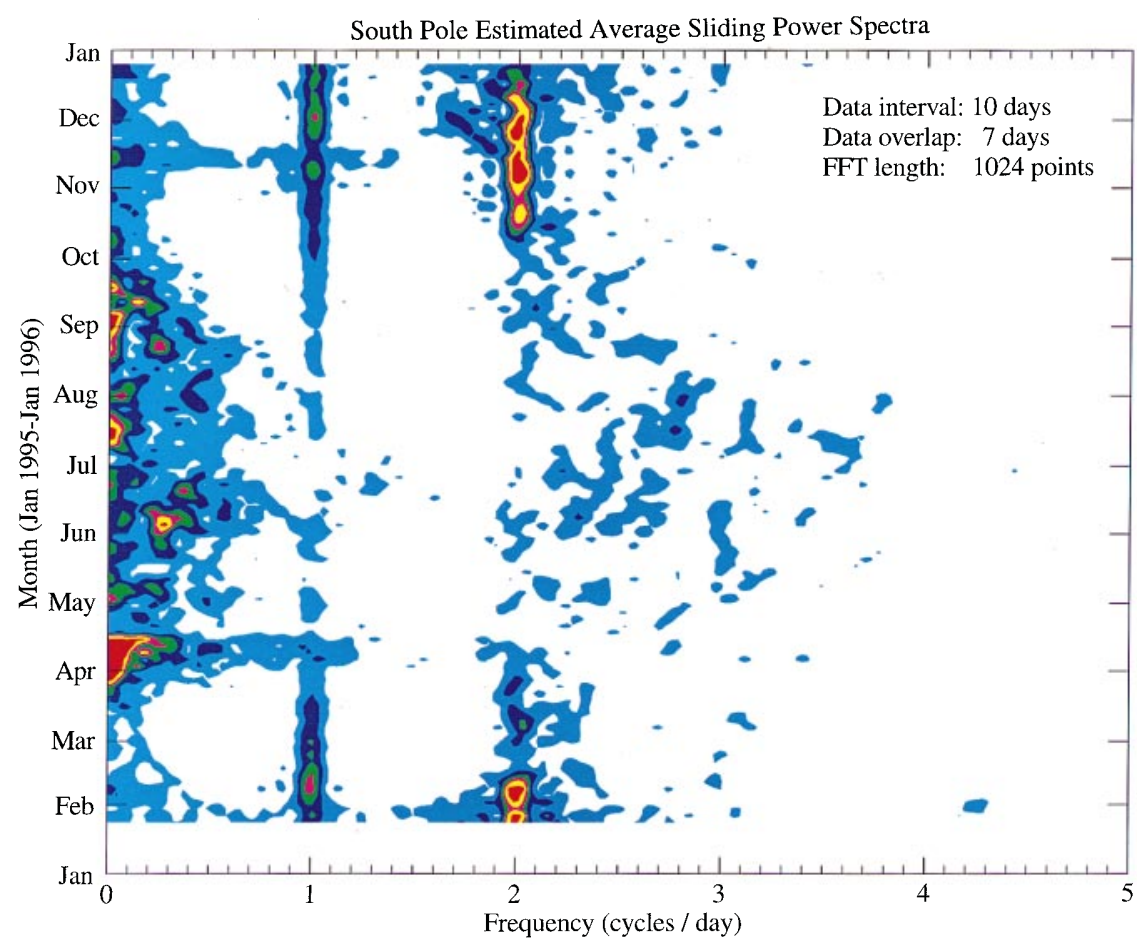

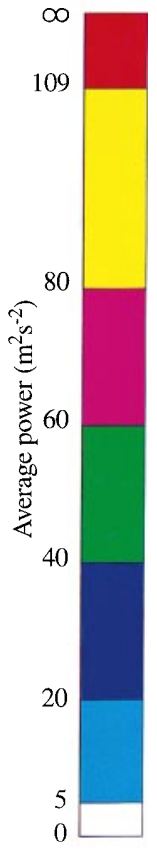

Fig. 1. Average spectrogram of the hourly meridional winds over the four directions of measurement. The spectrogram is formed by sliding 10-day spectra in increments of 3 days from 19 January 1995 to 26 January 1996 

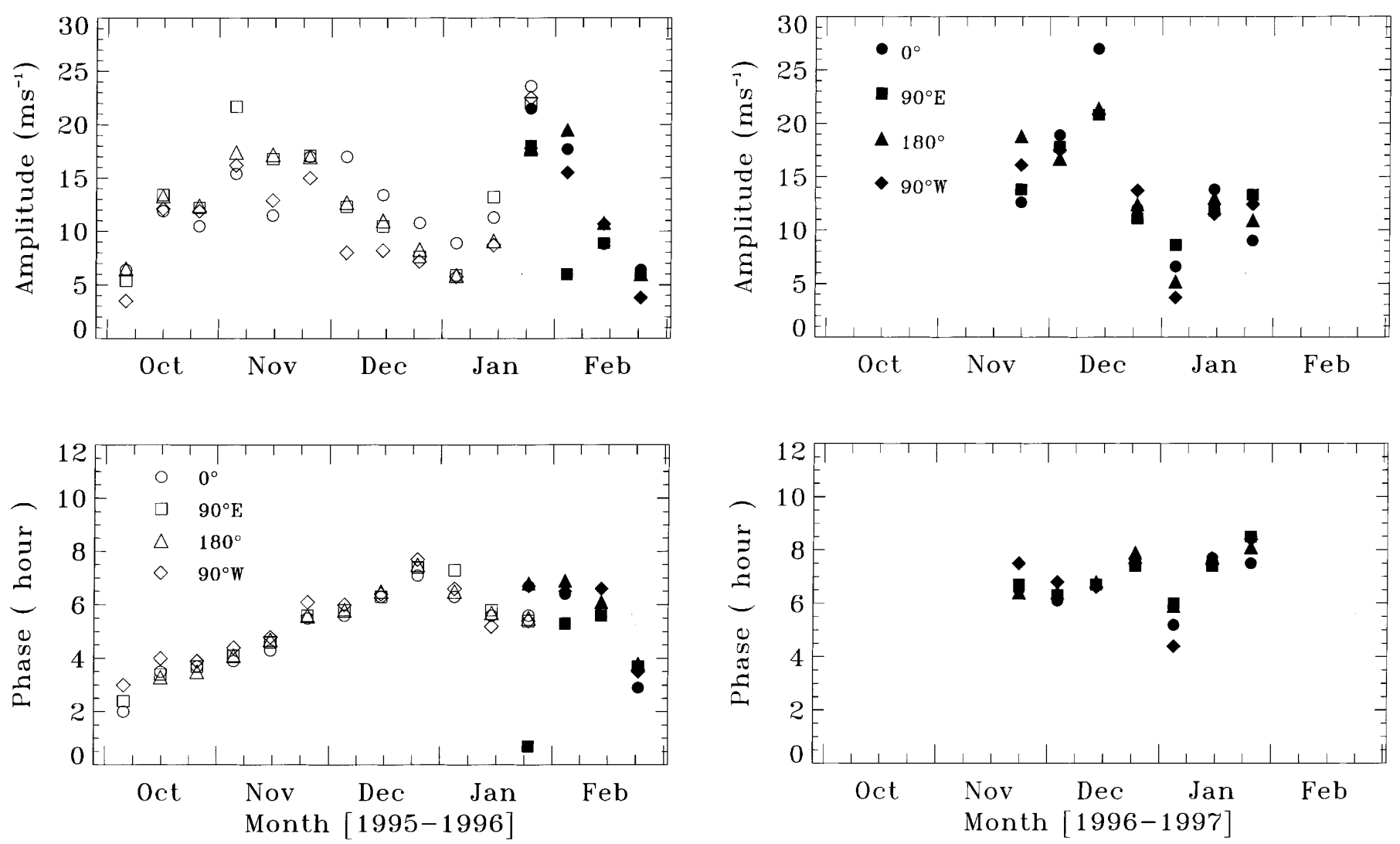

Fig. 2. Ten-day vector-average amplitudes and phases for the 12-h oscillation from 1 October 1995 through 26 January 1996 (open symbols) and 19 January 1995 to 18 February 1995 (filled symbols). The phases for all azimuth measurements were reduced to a single azimuth under the assumption of a zonal wavenumber $s=1$ oscillation which is westward propagating

anticipated, the absolute values of the phases and their lags for different directions confirm a westward propagating wave with a zonal wavenumber of one.

Another example of the intraseasonal variation of the 10-day mean amplitudes and phases of 12-h oscillation is shown in Fig. 3 for the period November 1996 to January 1997. In this figure, as in the previous one, the phases in all directions were reduced to one direction. Comparing this figure with Fig. 2, the dominant intraseasonal variations are seen to persist from one year to the next.

The data shown in Figs. 2 and 3 support our conclusion that the summertime 12-h oscillation observed at the South Pole possesses a zonal wavenumber of one. Additionally, this $12-\mathrm{h}$ phenomenon propagates westward and is a regular feature of the lower thermosphere over the South Pole during summer. To illustrate the phase propagation on a daily basis, a plot of the phases versus longitude (measurement direction) for several typical individual days is shown in Fig. 4. The diagonal lines in this figure correspond exactly to the phase variation of a westward propagation wave with $s=1$, and do not correspond to linear fits to the illustrated data points.

To investigate the day-to-day variability of the amplitudes of the 12-h oscillation, a daily harmonic fit

Fig. 3. Same as Fig. 2, except for November 1996-January 1997

was computed. The fitting window was slid by $6 \mathrm{~h}$ such that there were $18 \mathrm{~h}$ of overlap between consecutive fits. The resulting estimated semidiurnal amplitudes from each direction were detrended (cutoff period is equal to 50 days) and then averaged using a vector average to provide an estimate of the coherent semidiurnal wave structure present in all four measurement directions. Additionally, correlation coefficients were computed for the semidiurnal amplitudes from each of the four directions prior to averaging. The correlation matrix with these coefficients and their errors at the 95\% confidence level for the period from 16 November 1995 to 26 January 1996 when this semidiurnal oscillation is large, is given in Table 1.

Table 1 shows that day-to-day variations in the amplitude of the semidiurnal tides for all four measurement directions are highly correlated. Figure 5 illustrates the daily vector averaged (over four azimuth directions) semidiurnal amplitudes for the same timeperiod as for the data used in Table 1. Figure 6a shows the frequency content of the daily semidiurnal amplitude calculated from the periodogram analysis of the data shown in Fig. 5. From these figures it can be seen that the daily variation in the amplitude of the 12-h oscillation is characterized by several very specific periodicities, namely 4.5, 7.5, 11, and 20 days. Each of the corresponding peaks in the periodogram of Fig. 6a exceeds the $95 \%$ significance level. Similarly, for the 1996-1997 summer season (November 1996-January 1997) we have detected using the same analysis methods 

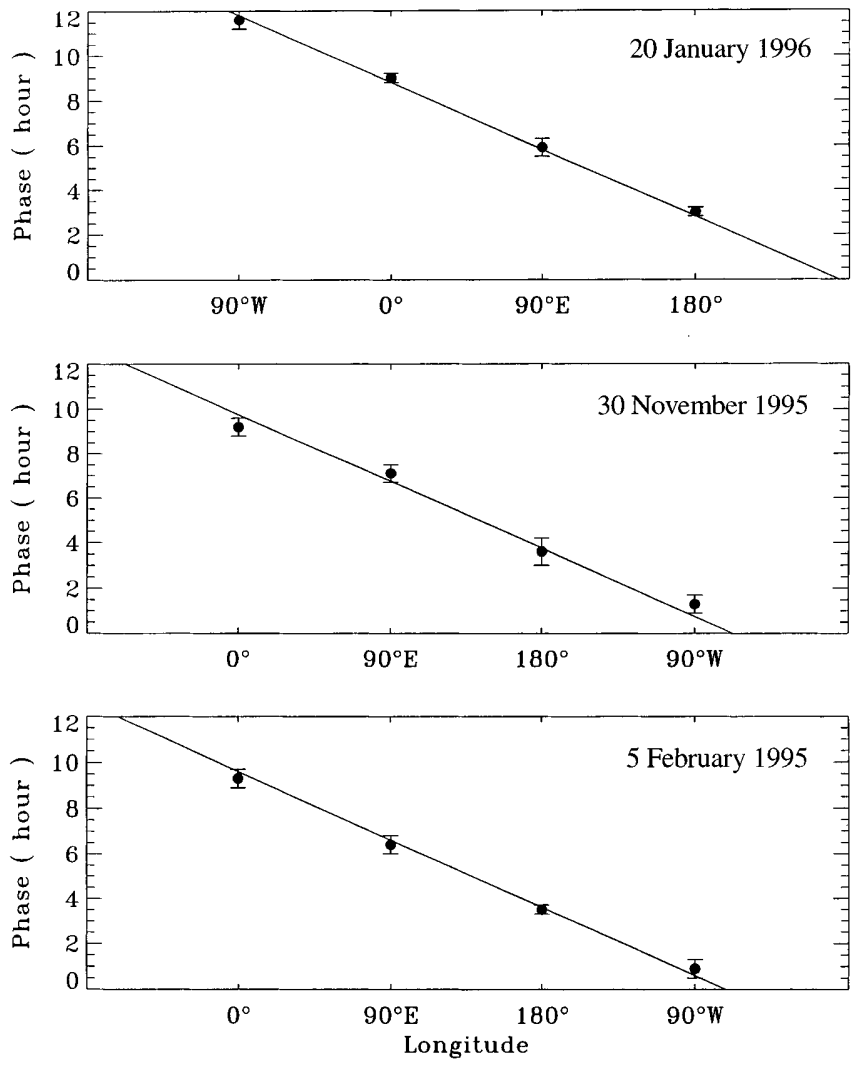

Fig. 4. Phase (UT of maximum) vs. longitude for 3 individual days of measurement, illustrating the zonal wavenumber one character of the oscillation

Table 1. Correlation coefficients between different observing directions and their errors (in parentheses) for hourly measurements between 16 November 1995 and 26 January 1996

\begin{tabular}{lllll}
\hline & 1 & 2 & 3 & 4 \\
\hline 1 & 1.00 & $0.70(0.07)$ & $0.69(0.08)$ & $0.76(0.06)$ \\
2 & $0.70(0.07)$ & 1.00 & $0.65(0.09)$ & $0.75(0.06)$ \\
3 & $0.69(0.08)$ & $0.65(0.09)$ & 1.00 & $0.72(0.07)$ \\
4 & $0.76(0.06)$ & $0.75(0.06)$ & $0.72(0.07)$ & 1.00 \\
\hline
\end{tabular}

the following significant periods: $3.5,4.5,8.5$ and 17.5 days (see Fig. 6b). We have determined that for all of these oscillations the maximum values occur in all directions simultaneously, and hence they correspond to a zonal wavenumber of zero. Therefore, we may conclude that the observed semidiurnal oscillation is strongly modulated by waves with periods typical of synoptic or planetary-scale disturbances.

\section{Interpretation of the results}

In this section we attempt to interpret our observational results. In the following subsection, some inferences are drawn based on climatological data available from other stations on the Antarctic continent. In Sects. 4.2 and 4.3, two hypotheses to explain the origin of the 12-h $s=1$ oscillation are outlined. Section 4.4 discusses the ap-

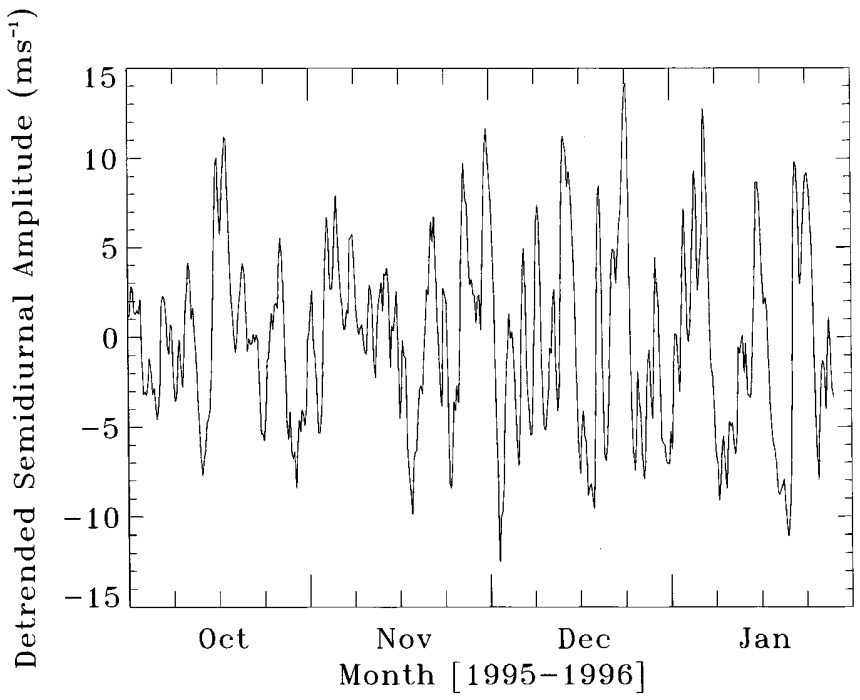

Fig. 5. Time-series of detrended amplitudes of the coherent semidiurnal oscillation during October 1995-January 1996. This time-series was formed by first sequentially fitting 24-h blocks of data, every $6 \mathrm{~h}$ and in each azimuth direction, with a 12-h sinusoid. The time-series of semidiurnal oscillations in each direction were detrended and then vector averaged to obtain the coherent semidiurnal oscillation present in all four measurement directions

pearance of this oscillation in a recent General Circulation Model (GCM) simulation, suggesting yet a third possible mechanism for generating this wave component.

\subsection{Inferences from climatological data}

First we will compare the seasonal behavior of the amplitudes of the 12-h oscillation in the lower thermosphere over the South Pole with those at other latitudes in the Antarctic. In Fig. 7 the climatological monthly mean amplitudes of the semidiurnal oscillation (meridional component) at $95 \mathrm{~km}$ are shown for Mawson $\left(67^{\circ} \mathrm{S}, 63^{\circ} \mathrm{E}\right)$, Molodezhnaya St. $\left(68^{\circ} \mathrm{S}, 45^{\circ} \mathrm{E}\right)$, Scott Base $\left(78^{\circ} \mathrm{S}, 170^{\circ} \mathrm{E}\right)$ (see Portnyagin et al., 1993a, b). It can be inferred from this figure that for Mawson and Molodezhnaya the seasonal variations of the amplitudes are very similar and can be characterized by a definite minimum (less than $5 \mathrm{~m} / \mathrm{s}$ ) in austral summer months. In contrast, at Scott Base the amplitudes attain their maximum values (almost $30 \mathrm{~m} / \mathrm{s}$ ) in the summer season. Additionally, at Scott Base the amplitudes observed in January are about 1.5 times smaller than those observed in December and February. This effect may also be observed in any individual year and is not a result of averaging over multiple years. Comparison of the longterm behavior of the amplitudes for Scott Base and South Pole (cf. also Figs. 2 and 3) shows that at both stations the magnitude of the amplitudes and their variations from one month to the next in the summertime are very similar. The values of the phases at Scott Base in summertime at $95 \mathrm{~km}$ and those at South Pole in the $180^{\circ}$ azimuth direction (closest in longitude to Scott 


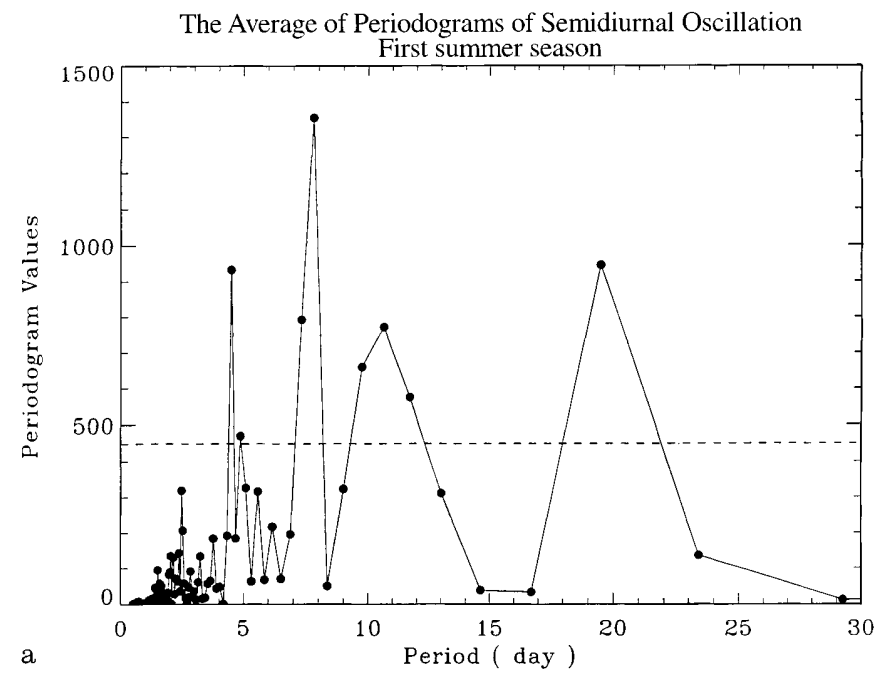

The Average of Periodograms of Semidiurnal Oscillation Second summer season

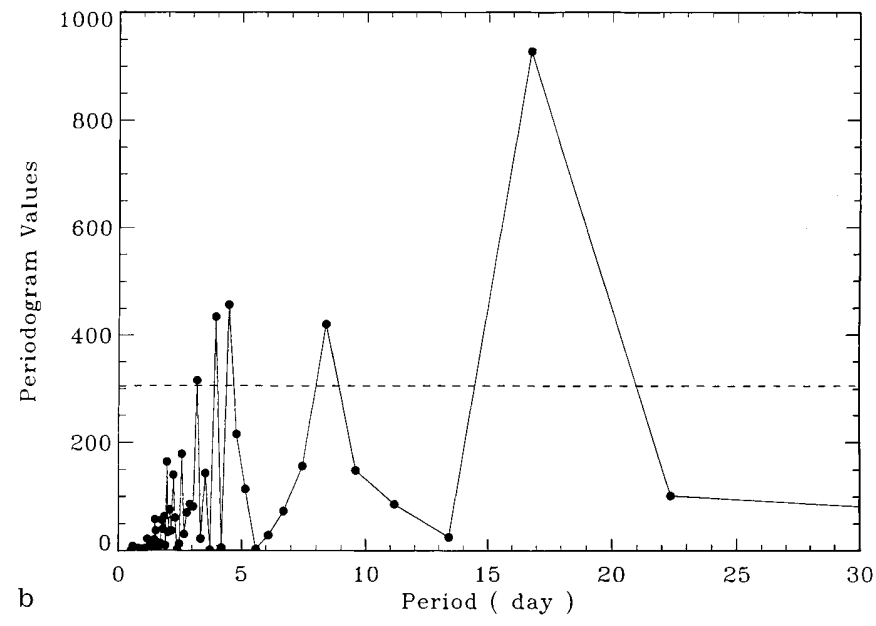

Fig. 6. a Spectrum of the time-series of Fig. 5. b As in part a, except corresponding to November 1996-January 1997

Base) are also in very good agreement, suggesting that the 12-h oscillations at both locations possess zonal wavenumber one. The small amplitudes of the 12-h oscillation at Mawson and Molodezhnaya probably indicate that the semidiurnal oscillation with $s=1$ is confined to latitudes greater than about $70^{\circ} \mathrm{S}$ in summer season. Our modeling result shown in the following is consistent with this conclusion.

Some further insight into the problem can be realized through examination of the phases, which are depicted in the lower panel of Fig. 7 and defined according to local time of maximum. The longitudes of Molodezhnaya $\left(45^{\circ} \mathrm{E}\right)$ and Mawson $\left(63^{\circ} \mathrm{E}\right)$ are roughly $120^{\circ}$ west of Scott Base $\left(170^{\circ} \mathrm{E}\right)$ and the $180^{\circ}$ azimuth beam of the South Pole radar. During April, May, July, and August the phases at Scott Base, Molodezhnaya, and Mawson are within about $1 \mathrm{~h}$ of $0100 \mathrm{LT}$; a constant phase with respect to longitude is consistent with a semidiurnal oscillation migrating with the apparent motion of the sun (i.e., sun-synchronous, which implies $s=2$ for a 12$\mathrm{h}$ oscillation). (The phase at Scott Base during June is an exception.) During the months October-February the
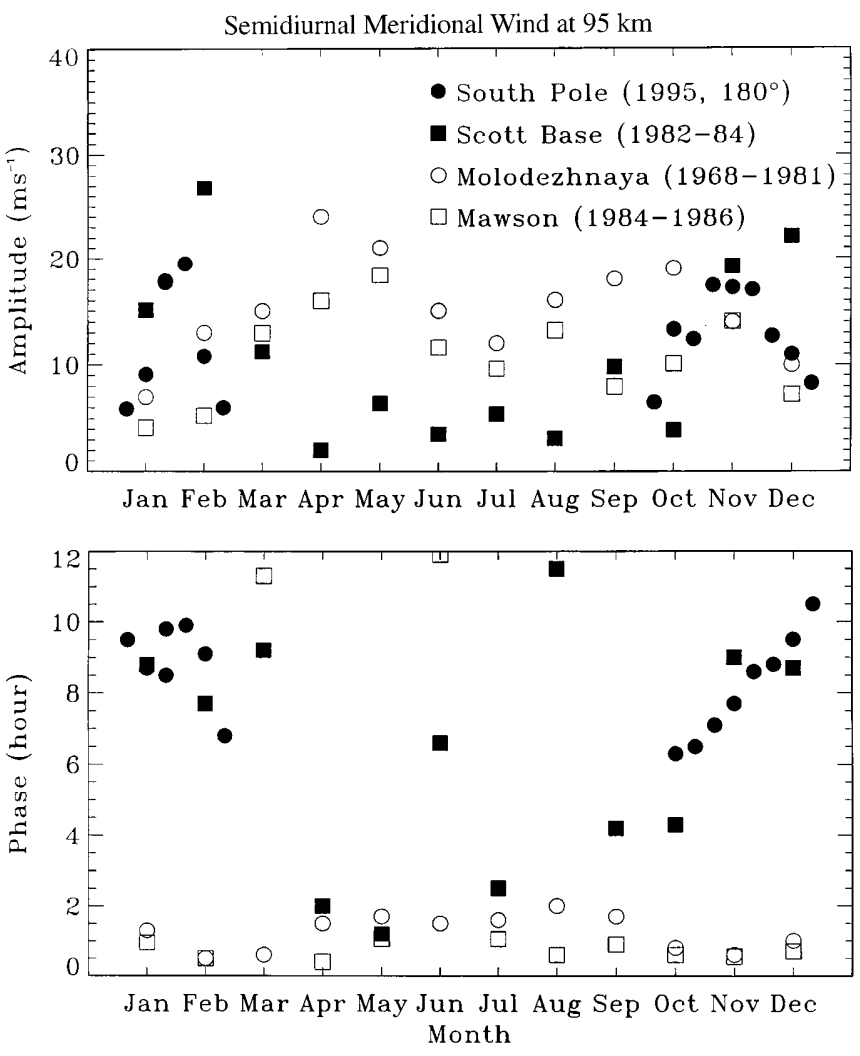

Fig. 7. Climatological amplitudes and phases (local times of maxima) of the semidiurnal oscillation in meridional wind at $95 \mathrm{~km}$ from four Antarctic stations. The South Pole measurements (filled circles) correspond to 1995 in the $180^{\circ}$ longitude azimuth direction, towards Scott Base $\left(78^{\circ} \mathrm{S}, 170^{\circ} \mathrm{E}\right)$. The Scott Base data (solid squares) correspond to $1982-1984$. The Molodezhnaya $\left(68^{\circ} \mathrm{S}, 45^{\circ} \mathrm{E}\right)$ data (open circles) represent averages over the years 1968-1981, and the Mawson $\left(67^{\circ} \mathrm{S}, 63^{\circ} \mathrm{E}\right)$ data (open squares) correspond to $1984-1986$

pattern is much different. Here the phases in the $60^{\circ} \mathrm{E}$ sector (i.e., Molodezhnaya and Mawson) lead (lag) those in the $180^{\circ} \mathrm{E}$ sector (i.e., Scott Base and the $180^{\circ}$ azimuth beam of the South Pole radar) by 8 (4) h. If we assume for the moment that the phases in both longitude sectors are independent of latitude, then the preceding phase differences are inconsistent with a sunsynchronous tidal oscillation.

Since the oscillation appears to be $s=1$ between $78^{\circ}$ and $88^{\circ} \mathrm{S}$ in the $180^{\circ}$ longitude sector, we may ask what phase in the $60^{\circ}$ longitude sector is consistent with the assumption of $s=1$ ? This can easily be calculated by understanding that propagation of a fixed phase of a zonally propagating oscillation is determined by the constraint $\sigma t+s \lambda=$ constant, where $\sigma=$ wave frequency $\left(2 \pi \mathrm{h}^{-1}\right), \quad t=$ universal time $(\mathrm{h}), s=$ zonal wavenumber, and $\lambda=$ longitude (radians). In terms of local time $t_{L}$ and longitude expressed in degrees the constraint becomes

$\sigma\left(t_{L}-\lambda / 15\right)+s \lambda=\sigma\left(t_{L}-\lambda / 15\right)+s \lambda$,

where the left-hand side corresponds to the $180^{\circ}$ longitude sector $\left(t_{L}=0900 \mathrm{~h}, \lambda=180^{\circ}\right)$ and the righthand side corresponds to $\lambda^{\prime}=60^{\circ}$ and $t_{L}^{\prime}$ remains to be found, assuming $s=1$. Putting in the numbers, 
$t_{L}^{\prime}=0500 \mathrm{~h}$. Thus the observed phases of approximately $0100 \mathrm{~h}$ near $60^{\circ} \mathrm{E}$ are not consistent with either $s=1$ or $s=2$, and it is conjectured that the semidiurnal wind oscillation observed near $68^{\circ} \mathrm{S}$ may reflect the presence of two zonal wavenumbers during the summer season.

For each season the foregoing analysis assumes that the phase of the semidiurnal tidal oscillation is constant with latitude between $68^{\circ} \mathrm{S}$ and $78^{\circ} \mathrm{S}$ (the phases at $78^{\circ} \mathrm{S}$ and $88^{\circ} \mathrm{S}$ are seen to be the same in the $180^{\circ} \mathrm{E}$ longitude sector when the 12-h $s=1$ oscillation is observed from the Pole.) This assumption can only be verified by simultaneous measurements at different longitudes at the same latitude, which is an experiment that hopefully will be conducted sometime in the future.

\subsection{In situ excitation hypothesis}

Given that the 12-h oscillation observed at Scott Base is zonal wavenumber $s=1$ (see preceding discussion), we examine the vertical structure of the 12-h oscillation at Scott Base for some possible clues as to its origin. In Fig. 8 vertical structures of the amplitudes and phases of the 12-h oscillation at Scott Base are illustrated for several months close to the summer season. It can be seen from this figure that the phase of the 12-h oscillation in the $80-100-\mathrm{km}$ height region indicates a nonlinear variation with height. For the summer months below about $85-87 \mathrm{~km}$ the phase gradient is, in general, positive or near to zero. Above these heights the gradient is negative and the vertical wavelength is estimated to be about $45 \mathrm{~km}$. This phase behavior may correspond to that situation when the source of excitation for the semidiurnal oscillation is situated somewhere in the mesosphere or lower thermosphere, say between 80 and $90 \mathrm{~km}$. It is impossible to place the source any higher, because the vertical gradient of the phase of the observed oscillation corresponds to upwards energy propagation starting at about $90 \mathrm{~km}$. One must also keep in mind that there are no height measurements available for the South Pole data and the only available information about the vertical structure of 12-h oscillation is from the Scott Base station, where determination of the zonal wave number is impossible.

To check the possibility that the observed semidiurnal oscillation may be a forced oscillation, a numerical simulation has been perfomed. The model employed is very similar to that described in Forbes and Vial (1989), i.e., it solves for the tidal fields as linearized perturbations on a background state characterized by mean zonal winds, vertical temperature gradients, and eddy and molecular diffusion parameterized by an effective Rayleigh friction. However, in the present model the horizontal structures of the tidal fields are described by a truncated series of Legendre polynomials instead of employing the grid-point numerical formulation as in Forbes and Vial (1989). The Rayleigh friction parameterization (e.g., Vial and Forbes, 1989) utilizes the eddy diffusion values from Garcia and Solomon (1985) and the molecular diffusion model of Forbes and Garrett (1979) with the assumption of a $50-\mathrm{km}$ vertical wavelength as is indicated in the Scott Base measurements (Fig. 8). The mean wind model for January conditions is based on Fleming et al. (1988) below $70 \mathrm{~km}$, and is merged with the Portnyagin and Solov'yeva (1992a, b) model above $80 \mathrm{~km}$ in the manner described by Hagan et al. (1993). Arbitrary source distributions can be accommodated.

Numerical experiments were performed with various forms of the source distribution. One that produced the closest fit to observations has a vertical distribution of Gaussian form with maximum $\left(0.000025 \mathrm{erg} \mathrm{s}^{-1} \mathrm{~m}^{-3}\right)$ at $84 \mathrm{~km}$ and half-width of about $12 \mathrm{~km}$. The latitude
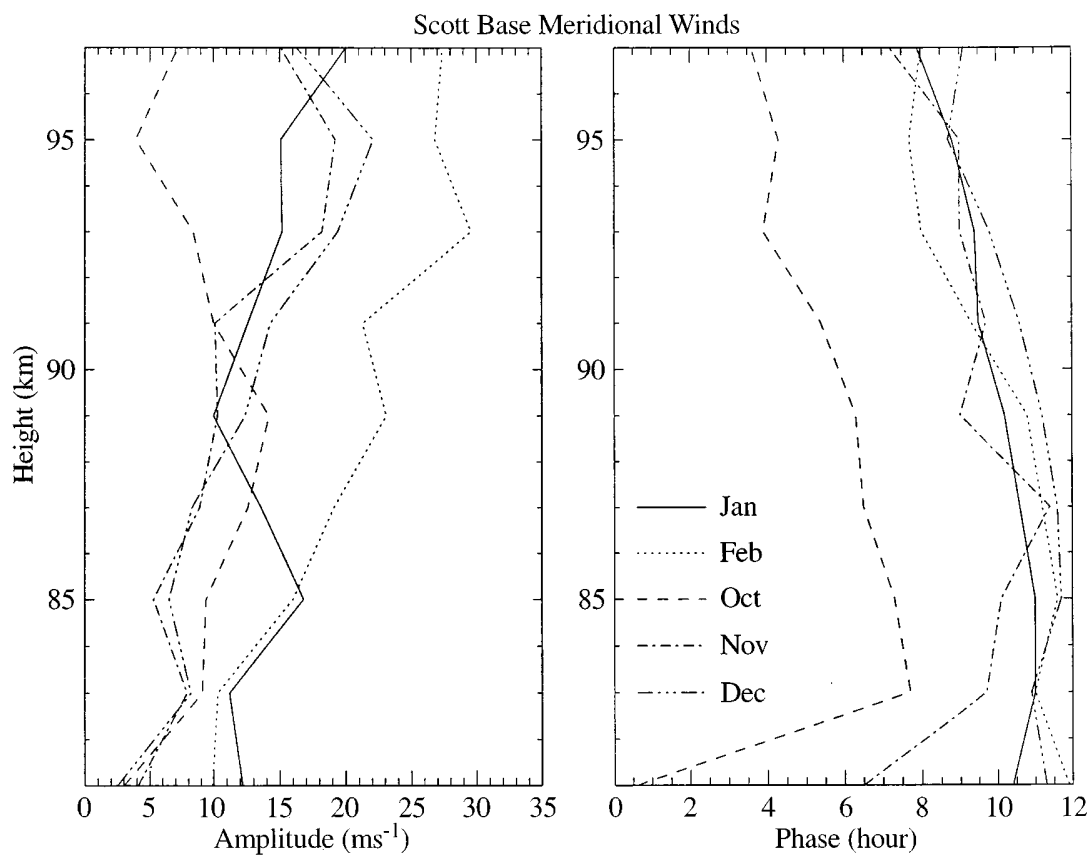

Fig. 8. Monthly mean amplitude and phase vertical structures of the semidiurnal component of meridional wind over Scott Base. Standard deviations during January are $1.0 \mathrm{~ms}^{-1}$ and $0.1 \mathrm{~h}$ between $85-95 \mathrm{~km}$, and up to $2 \mathrm{~ms}^{-1}$ and $0.3 \mathrm{~h}$ above and below. Standard deviations are slightly higher during other months between $85-95 \mathrm{~km}$, reaching values up to $3 \mathrm{~ms}^{-1}$ and $0.5 \mathrm{~h}$ at 72 and $100 \mathrm{~km}$ (data provided by G. Fraser) 
distribution is that of a half-sinusoid with maximum at $70^{\circ}$ latitude and width of $40^{\circ}$. The amplitudes and phases of the meridional wind for the 12-h $s=1$ oscillation from this model are depicted in Fig. 9. At $78^{\circ} \mathrm{S}$ the model amplitudes between 87 and $95 \mathrm{~km}$ reasonably approximate the measurements, but are significantly smaller below and above these heights, respectively. The latitude distribution of amplitude, however, represents a best fit to the latitudinal distribution of amplitudes for the four stations South Pole, Scott Base, Molodezhnaya, and Mawson (see Fig. 9); the amplitude at Scott base is underestimated, while the amplitude at South Pole is overestimated. The vertical distribution of phase is similar to that at Scott Base, with evanescent behavior below $90 \mathrm{~km}$ and propagating behavior above this height. Moving the height and latitude of heating maximum by any more than about $5 \mathrm{~km}$ and $10^{\circ}$, respectively, led to wind distributions which did not suitably approximate the observed values depicted in Fig. 9.

While we have reproduced the salient features of observations with this model result, the assumed heating is totally ad hoc. The possible realistic heat sources include insolation absorption, perhaps by a secondary ozone maximum; chemical heating by exothermic reactions; or perhaps even joule or particle heating. There is evidence that the polar vortex around the South Pole in the lower thermosphere is displaced from the geographic
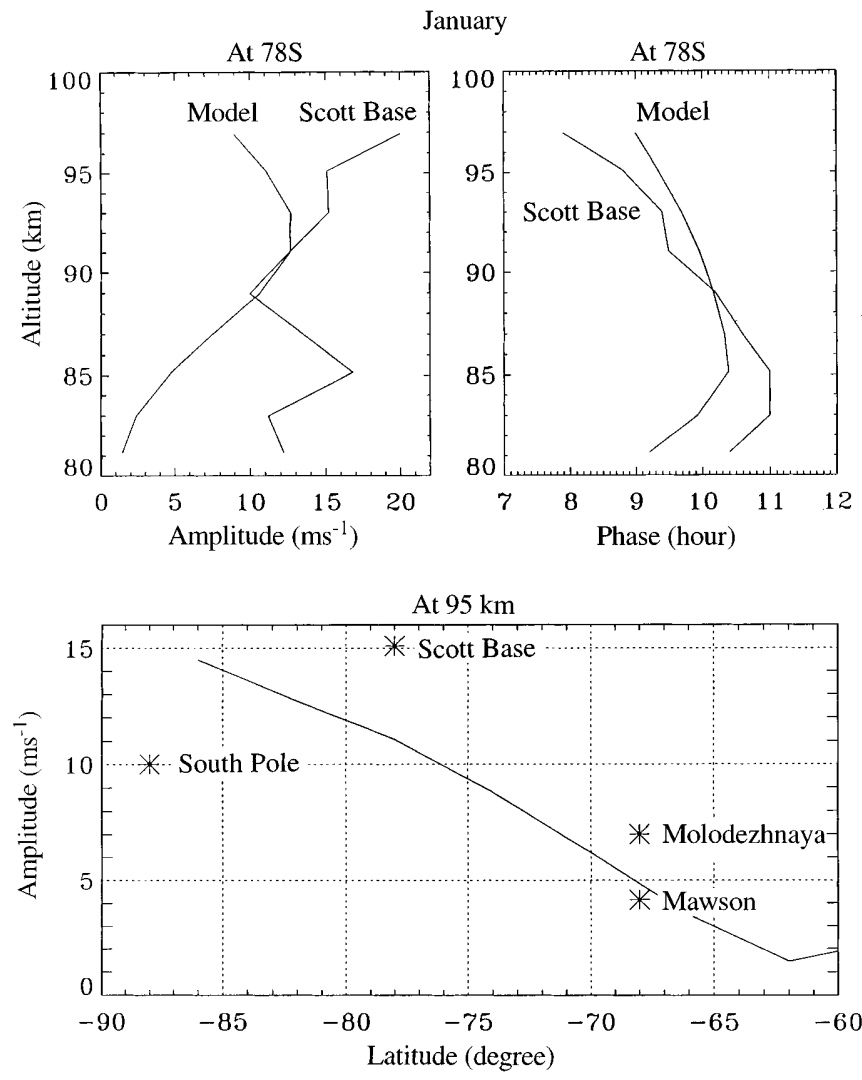

Fig. 9. Comparison of observed January mean semidiurnal tide in meridional wind with model results. Top: comparison of amplitude and phase vertical structures with those at Scott Base. Bottom: latitude variation in amplitudes at $95 \mathrm{~km}$ pole, which is equivalent to a zonal wavenumber one stationary structure (Hernandez et al., 1992b; Portnyagin et al., 1997). It is probable that the chemical species concentrations also possess a significant stationary wave-1 structure; however, it is uncertain why the 12-h component of the oscillation would be preferentially excited over the 24-h component, if the wave were excited by solar radiation absorption by ozone, for instance. The answer may lie in the recent study by Meyer and Forbes (1997), who demonstrate that the 12h $s=1$ oscillation is close to a quasi-resonant response of the lower thermosphere. On the other hand, one might expect that an in situ excitation source would produce intraseasonal variations in the diurnal and semidiurnal wind amplitudes that are correlated, but this is not the case for this data set.

\subsection{Nonlinear interaction hypothesis}

One hypothesis that has been put forth to explain the existence of the 12-h $s=1$ oscillation is the nonlinear interaction between the 12-h $s=2$ migrating semidiurnal tide and a stationary $s=1$ feature (Forbes et al., 1995; Portnyagin et al., 1997). According to this idea, the nonlinear interaction between the stationary $s=1$ background wind distribution:

$u=u_{0}^{+} e^{i \lambda}+u_{0}^{-} e^{-i \lambda}$

and the migrating semidiurnal tide:

$v=v_{2}^{+} e^{i(\sigma t+2 \lambda)}+v_{2}^{-} e^{-i(\sigma t+2 \lambda)}$

gives rise to $s=1$ and $s=3$ semidiurnal oscillations, where $\lambda$ is longitude, $\sigma$ is the semidiurnal wave frequency $(2 \pi / 12) h^{-1}$ and the coefficients in the expressions are complex. The $s=3$ component is not observable at the pole (see Forbes et al., 1995; Hernandez et al., 1992a, b, 1995), but may exist away from the pole. Forcing for the $s=1$ semidiurnal component would have the following form under the nonlinear interaction hypothesis:

$v=\frac{2 i}{a \sin \theta}\left[v_{2}^{+} u_{0}^{-} e^{i(\sigma t+\lambda)}+v_{2}^{-} u_{0}^{+} e^{-i(\sigma t+\lambda)}\right]$,

where $\theta$ is the colatitude. Now, it is not necessary that this interaction takes place in the same atmospheric region in which the 12-h $s=1$ oscillation is observed; for instance, such an interaction could take place at lower heights and the $s=1$ oscillation could propagate upwards into the $95-\mathrm{km}$ region. Again, as already noted, the possible quasi-resonance of the lower thermosphere (Meyer and Forbes, 1997) at a period of $12 \mathrm{~h}$ could lead to an amplification of the response to a relatively moderate excitation source.

Does a stationary $s=1$ feature exist to interact with the semidiurnal migrating tide? - probably yes. Evidence exists in the South Pole meteor wind data (Portnyagin et al., 1996) for a stationary $s=1$ component near the mesopause that is interpreted as the signature of a circumpolar vortex which is displaced with respect to the geographic pole (see also Hernandez et al., 1992b). Geopotential charts constructed by Koshelkov (1984) 
for the southern hemisphere also provide evidence for a displaced circumpolar vortex. In addition, McLandress and McFarlane (1993) show that in the northern hemisphere a zonally asymmetric orographic gravity wave source, when interacting with the strato-mesospheric stationary wave, can amplify and extend the $s=1$ stationary feature into the lower thermosphere. Such an effect could also be present in the southern hemisphere if the tropospheric gravity wave source is zonally asymmetric.

An obvious way to test the foregoing hypothesis is to simulate the scenario with a physics-based mechanistic model. However, such a numerical experiment remains to be performed.

\subsection{The $12-h s=1$ oscillation in a GCM simulation}

To the authors' knowledge, the only numerical simulation which has revealed the signature of a 12-h $s=1$ oscillation in the polar mesopause region is that of Miyahara and Miyoshi (1997) using the Middle Atmosphere Circulation Model at Kyushu University (MACMKU). MACMKU is a GCM which extends from the earth's surface to the lower thermosphere, and which includes a diurnal cycle throughout the model domain. The only simulation provided by Miyahara and Miyoshi (1997) is for equinox conditions, but for this case they find a $5-15 \mathrm{~ms}^{-1}$ meridional wind for the 12-h $s=1$ oscillation near $90^{\circ}$ north latitude around $95 \mathrm{~km}$. Interestingly, they also find a 12-h $s=3$ oscillation at midlatitudes between 100 and $150 \mathrm{~km}$ of order 15 $20 \mathrm{~ms}^{-1}$, or about half that of the migrating $(s=2)$ oscillation. Recall that the nonlinear interaction hypothesis put forth by Forbes et al. (1995), see Sect. 4.2, predicts an $s=1$ and $s=312$-h oscillation assuming that a stationary $(s=1)$ wave component exists.

The results of Miyahara and Miyoshi (1997) are inconclusive in that they are not able at the present time, within the confines of their GCM, to isolate the causeeffect relationship which leads to the aforementioned $s=1$ and $s=312-\mathrm{h}$ oscillations. In addition, their simulation is for equinox, not solstice, and the $s=112$ $\mathrm{h}$ oscillation appears in the northern hemisphere. They do discard the possibility of zonal variations in ozone concentration (and therefore in ozone heating) exciting the 12 -h $\mathrm{s}=1$ wave, since a zonally symmetric ozone distribution is assumed in their model. The existence of an $s=1$ stationary feature in the zonal wind system is not mentioned. They point to the following tropospheric sources as the most likely candidates for exciting the nonmigrating semidiurnal tides: (1) vertical eddy heat transport in the planetary boundary layer (PBL); (2) convective heating; and (3) zonally inhomogeneous water vapor insolation absorption. In support of this, analyses of the Japanese Meteorological Institute GCM (Tokioka and Yagai, 1987) also point to tropospheric heating, particularly heat fluxes in the PBL, as potentially important for exciting diurnal and semidiurnal nonmigrating tides (see also Tsuda and Kato, 1989), but their model does not extend above the stratosphere.
Interestingly, besides the tropics, the other major PBL heating region during January in this GCM is over the Antarctic continent. However, although these studies are promising, it is premature to arrive at definitive conclusions yet. It appears that further progress in identifying cause-effect relationships for the 12-h $s=1$ oscillation will require, in part, comprehensive study of tropospheric tidal heat sources within the confines of more mechanistic models which allow for isolation and examination of the various individual sources of excitation.

\section{Conclusions}

Analyses of our first long-term continuous meteor radar wind measurements in the lower thermosphere over the South Pole reveal a westward - propagating semidiurnal oscillation with zonal wavenumber $s=1$ that is present throughout most of the summer season. The salient characteristics of this oscillation are consistent between the two consecutive November-January summer periods analyzed here. The well-known migrating semidiurnal tide with $s=2$ is absent in the vicinity of the South Pole, in accord with the theoretical arguments of Hernandez et al. (1992a).

The observed semidiurnal wind oscillation reflects significant day-to-day variability at typical synopticscale periods, suggesting that modulation of this oscillation by a planetary waves is occurring. The region where this wave-wave interaction takes place has not been identified, but there are some indications that this may occur outside the polar lower thermosphere region.

The actual mechanisms responsible for the excitation and propagation of the observed semidiurnal wind oscillation with $s=1$ have yet to be identified. Those discussed herein include excitation in the upper mesosphere, nonlinear interaction between the migrating semidiurnal tide and a stationary $s=1$ feature, and thermal excitation in the troposphere. Final resolution of the problem requires comprehensive numerical simulations with special attention to processes specific to the near-polar region.

The obtained results give rise to the very important question: Is the observed oscillation characteristic of only the high-latitude Antarctic upper atmosphere, or is it a common phenomenon for both the Antarctic and Arctic?

Acknowledgements. The authors deeply appreciated Dr. G. J. Fraser for providing us measurement results for Scott Base St. in a tabulated form. This work was partly supported by National Science Foundation (Grant OPP-9320879) and by Russian Fund for Fundamental Researches (Grant N 96-05-64301).

Topical Editor F. Vial thanks T. Aso and M. J. Jarvis for their help in evaluating this paper.

\section{References}

Fleming, E. L., S. Chandra, M. R. Shoeberl, and J. J. Barnett, Monthly mean global climatology of temperature, wind, geopotential height, and pressure for $0-120 \mathrm{~km}$, NASA Tech. Memo. 100697, 1988. 
Forbes, J. M., and H. B. Garrett, Theoretical studies of atmospheric tides, Rev. Geophys. Space Phys., 17, 1951-1981, 1979.

Forbes, J. M., and F. Vial, Monthly simulations of the solar semidiurnal tide in the mesosphere and lower thermosphere, $J$. Atmos. Terr. Phys., 51, 649-662, 1989.

Forbes, J. M., N. A. Makarov, and Yu. I. Portnyagin, First results from the meteor radar at south pole: a large 12-hour oscillation with zonal wavenumber one, Geophys. Res. Lett., 22, 32473250, 1995.

Fraser, G. J., G. Hernandez, and R. W. Smith, Eastward-moving $2-$ 4 day waves in the winter Antarctic, Geophys. Res. Lett., 20, 1547-1550, 1993.

Garcia, R. R., and S. Solomon, The effect of breaking gravity waves on the dynamics and chemical composition of the mesosphere and lower thermosphere, J. Geophys. Res., 90, 3850-3868, 1985.

Hagan, M. E., J. M. Forbes, and F. Vial, Numerical investigation of the propagation of the quasi-two-day wave into the lower thermosphere, J. Geophys. Res., 98, 23 193-23 205, 1993.

Hernandez, G., R. W. Smith, and J. Conner, Neutral wind and temperature in the upper atmosphere above South Pole, Antarctica, Geophys. Res. Lett., 19, 53-56, 1992a.

Hernandez, G., R. W. Smith, G. J. Fraser, and W. L. Jones, Largescale waves in the upper mesosphere at Antarctic high latitudes, Geophys. Res. Lett., 19, 1347-1350, 1992b.

Hernandez, G., G. J. Fraser, and R. W. Smith, Mesospheric 12hour oscillations near South Pole, Antarctica, Geophys. Res. Lett., 20, 1787-1790, 1993.

Hernandez, G., R. W. Smith, and G. J. Fraser, Antarctic highlatitude mesospheric dynamics, Adv. Space Res., 16, 71-80, 1995.

Hernandez, G., J. M. Forbes, R. W. Smith, Yu. I. Portnyagin, J. F. Booth, and N. A. Makarov, Simultaneous mesospheric wind measurements near South Pole by optical and meteor radar measurements, Geophys. Res. Lett., 23, 1079-1082, 1996.

Koshelkov, Yu. P., Climatology of the middle atmosphere of the Southern Hemisphere, J. Atmos. Terr. Phys., 46, 781-798, 1984.

McLandress, C., and N. A. McFarlane, Interactions between orographic gravity wave drag and forced stationary planetary waves in the winter Northern Hemisphere middle atmosphere, J. Atmos. Sci., 50, 1966-1990, 1993.
Meyer, C. K., and J. M. Forbes, Natural oscillations of the ionosphere-thermosphere-mesosphere (ITM) system, J. Atmos. Solar Terr. Phys., 59, 2185-2302, 1997.

Miyahara, S., and Y. Miyoshi, Migrating and nonmigrating atmospheric tides simulated by a middle atmosphere general circulation model, Adv. Space Res., 20, No. 6, 1201-1207, 1997.

Portnyagin, Yu. I., and T. V. Solov'yeva, An empirical model of the meridional wind in the mesopause/lower thermosphere, 1, a mean monthly empirical model, Ross. Meteorol. Gidrol., 10, 2835, 1992a.

Portnyagin, Yu. I., and T. V. Solov'yeva, An empirical model of the meridional wind in the mesopause/lower thermosphere, 2, height-latitude features of basic components of meridional wind seasonal variations, Ross. Meteorol. Gidrol., 11, 29-26, 1992b.

Portnyagin, Yu. I., J. M. Forbes, G. J. Fraser, R. A. Vincent, S. K. Avery, I. A. Lysenko, and N. A. Makarov, Dynamics of the Antarctic and Arctic mesosphere and lower thermosphere regions - I. The prevailing wind, J. Atmos. Terr. Phys., 55, 827-842, 1993a.

Portnyagin, Yu. I., J. M. Forbes, G. J. Fraser, R. A. Vincent, S. K. Avery, I. A. Lysenko, and N. A. Makarov, Dynamics of the Antarctic and Arctic mesosphere and lower thermosphere regions-II. The semidiurnal tide, J. Atmos. Terr. Phys., 55, 843-856, 1993b.

Portnyagin,Yu. I., J. M. Forbes, N. A. Makarov, and Eu. G. Merzlyakov, Main regularities of intradiurnal oscillations in the lower thermosphere over South Pole (in Russian), Rep. Russian Acad. Sci., 349, 104-105, 1996.

Portnyagin, Yu. I., J. M. Forbes, and N. A. Makarov, Unusual characteristics of lower thermosphere prevailing winds at South Pole, Geophys. Res. Lett., 24, 81-84, 1997.

Tokioka, T., and I. Yagai, Atmospheric tides appearing in a global atmospheric general circulation model, J. Meteorol. Soc. Jpn., 65, 423-437, 1987.

Tsuda, T., and S. Kato, Diurnal non-migrating tides excited by a differential heating due to land-sea distribution, J. Meteorol. Soc. Jpn., 67, 43-54, 1989.

Vial, F., and J. M. Forbes, Recent progress in tidal modeling, $J$. Atmos. Terr. Phys., 51, 663-671, 1989. 